\title{
The Opportunity for Zoos to Save
}

\section{Vanishing Species}

By William Conway

Zoos have a two-fold obligation: education, a field they have as yet scarcely tapped and where their opportunity is enormous, and captive breeding of endangered species, which is vital for some animals if they are to survive. The author, who is General Director of the New York Zoological Society, suggests that, if the facilities of to-day had been available, the dodo and the great auk could have been bred in zoos and released in the wild. He considers some of the criteria for selecting species to be bred, and lays down three basic rules for all captive breeding programmes: a large sample, scattered groups, and the elimination of atypical animals. He urges the need for an internationally co-ordinated plan for breeding endangered animals, and also, because the "know-how" of zoos is better than their facilities, the establishment of special, internationally supervised breeding centres.

MANY biologists now agree that national parks offer the best 1 practical solution for preserving wild creatures. But not all parks will be permanently inviolate, and not all wild creatures lend themselves to park management. It may be that zoos will become the second most important refuge for wild creatures as well as an essential supporting service for parks. In any event, as humans are increasing at a rate of more than 140,000 each day, almost $50,000,000$ every year, it seems inevitable that wildlands, outside of parks and reserves, will be largely destroyed. Fremlin, the British physicist, recently noted that the earth's population is now doubling every 37 years. He calculated that, for the next 260 years, this increase could be taken care of by the intensive use of all crop space, by eliminating meat-eating, by efficiently harvesting sea food and by exterminating all land wildlife. Most of us, however, believe that reason will prevail, that educational and governmental efforts will reduce birth rates, and even that crowding itself may have undefined effects of biological control upon man. But crowding there will be, and it is absurd to think of any park or its animal inhabitants as safe in perpetuity.

In the United States, the gradual water starvation of the Everglades National Park and the present threat to the Grand Canyon make it clear that parks are not sacrosanct even in the most fortunate countries. We are finding that public interest in wild lands and wild creatures is learned, not innate. It is based within the cultural continuum and tradition. For municipal man, wildlife and wild places are increasingly outside of his culture, outside of his language and even outside of his 
traditions. Clearly man can grow to dislike open spaces, to like crowded cities, to deny the conservationists' standards of environmental quality and to consider wild animals and parks an expendable luxury - even an insupportable reservoir of disease and agricultural pests.

The average real income of the 200 million people of North America is nearly twenty-five times higher than that, for example, of the 1,600 million people of Asia, to say nothing of Africa. Relatively speaking, we are not nearly so crowded and we are better educated, yet conservationists need to struggle fiercely to preserve our parks. It is obvious that in the developing nations of Africa, Asia and South America the struggle will be more severe; that existing preserves and parks will be lost from time to time, even as new ones are authorised. It is just as obvious that ever greater human populations with higher standards of living will demand immensely greater quantities of raw materials and resource utilisation whether the population increases or not. And it is clear that effective international birth control programmes are many years away.

However, it will not be many years before the usefulness of some national parks as wildlife habitat is substantially reduced. As our population rises its mobility increases, and wildlands shrink; and more visitors pour into our parks: this year, 6,000,000 to the Great Smokies, $2,000,000$ to Yellowstone. When there are too many visitors, roaming unrestricted in the parks, the more sensitive species may fail to breed; the larger predators may be deleted. The park can become a scenic area where visitors may see where the grizzly bear and, for that matter, the brontosaurus once walked.

But the problems of conservation in parks and refuges are more subtle than visitor pressure. We are mammals and, naturally enough, we often think in terms of mammals in developing parks and reserves and even zoos. Yet the great, usually obligatory, mobility of birds which impels them to range across political boundaries ignoring manmade boundaries, means that bird preservation, especially of larger species, in restricted park areas will frequently prove impractical. Whooping crane preservation is a case in point. The poikilothermic reptiles and amphibians with their low tolerance for chemical herbicides and pesticides, with often localised ranges, their dependence on microclimate and their comparative lack of selective mobility, pose almost insuperable problems to preservation in parks.

Of course, other non-zoo solutions besides preservation in parks have been suggested, and surely the conservationist will be well advised to diversify his portfolio. Direct economic utilisation of wildlife as food, as opposed to indirect utilisation through tourism and education, has been suggested and is being tried. There have been a few happy successes, but this is not a general solution to the long-term preservation of many species of wild animals. Even if it should prove acceptable, for example, to use various African antelopes for meat, husbandry 
efforts will accelerate the artificial succession of domestication: management, followed by farming, then by selection for special characteristics and, finally, by the production of new forms. Although such management is a valid concept in agricultural economics, especially in terms of total biomass production, it is one likely to affect few wild animals and then to remove them from the ranks of the wild. It should be advocated by conservationists to the degree that it stimulates habitat preservation. Parks are a more general solution, and support for the preservation of parks is really the greatest of zoo opportunities in the propagation of endangered species.

The zoo stands today as the one internationally widespread, publicly and privately supported, popular institution devoted to the maintenance and study of living wild creatures. Where better can the plight of a vanishing animal arouse public support than in educational presentations combined with the creature itself and located in man's metropolitan population centres? It seems strange that, in years gone by, conservationists have more often condemned than supported zoological exhibition. The tremendous educational potential of zoos has scarcely been tapped by conservationists. Yet, no other voluntarily attended cultural effort of civilised man draws such overwhelmingly high public attendance. The serious modern conservationist must not only seek zoo cooperation, he must seek zoo positions. Where better can he consistently promote, at the grass roots level, the climate necessary for the preservation of wild animals?

If conservation education is a zoo opportunity, propagation of endangered forms is a zoo obligation.

\section{What Might Have Been}

Obviously, captive propagation provides insurance against the protection "drought" which attends the birth of new nations in undeveloped parts of the world. When stability has been achieved, at least some of an area's wildlife may be re-established in parks from zoo stocks. Except for the usually undesirable introduction of animals in lands foreign to them, captive propagation is the only method for preserving those species whose habitats are totally destroyed or whose mobility and size make park preservation inadequate. It thus seems reasonable to inquire how captive propagation might have influenced the loss of animals which have recently become extinct.

Because of my special familiarity with birds, and because we usually talk about mammals, I have reviewed Colonel Vinoent's August 1965 IUCN List of Birds Known or Thought to Have Become Extinct Since 1600 , with captive propagation potential in mind. I have used a variety of objective criteria such as whether a closely related extant species has been bred, known and indicated feeding habits, breeding biology and manner of extinction, to help me evaluate the probable captive performance of each species. 
Colonel Vincent names 162 extinct birds. For 64 of these birds a lack of information on related forms, or a lack of related forms, completely intimidated me. Of the remaining 98 birds, 27 seemed unlikely candidates for propagation at the present stage of avicultural technology. Fifty-eight forms had characteristics, or modern relatives with characteristics, which suggest that the possibility of breeding them in captivity today would be a real one. You will be interested to know that I have included the elephant bird, the lesser moa and the dodo as strong possibilities among this group. The captive propagation of the 13 birds that remain, including the Carolina parakeet and the passenger pigeon, would be "likely" rather than simply a good possibility.

It is interesting to speculate what our present situation would be if we could have held the elephant bird in zoos for the last 300 years. Could it now be reintroduced in Madagascar? Politically, this might prove possible on special park lands and preserves. Ecologically, it might not. However, even if supplemental feeding were necessary, it seems likely that economic values in food and tourism might support such a project. At least we would still have the bird! The dodo might now find a welcome under managed conditions on Mauritius, and I think we can conclude that large flightless land birds might eventually have been reintroduced in parks. Flying species face more difficult problems in reintroduction.

Although the Carolina parakeet was bred in captivity a time or two and probably could have been bred in numbers, its predilection for agricultural crops might still prohibit its reintroduction in the USA. Yet its chances of reintroduction would be better than those of the travelling crop-loving passenger pigeon which also bred in captivity. Today, we might have a chance of propagating the great auk, and, if we did, we surely would have a good chance of reintroducing it. But our technology is not yet equal to the task of propagating such birds as the Guadaloupe storm petrel, the New Caledonian owlet frogmouth or the Laysan Island millerbird. Of course, our problem today is not spilt auks, rocs and moas, it is ne-nes and lammergeiers, whooping cranes and wekas. An evaluation of the propagation potential of living rarities is fascinating.

Beginning with Colonel Vincent's cautiously titled List of Rare Birds, including those thought to be so, but of which detailed information is still lacking, of February, 1965, I mixed several quarts of IUCN Red Book, miscellaneous references and personal recollections to develop some estimates of captive breeding potential for the 307 listed rarities. Again, this is a preliminary evaluation but one worth summarising if only to help stimulate the development of calculated guidelines for zoo breeding programmes.

To the criteria used in evaluating the propagation potential of extinct birds, we have been able to add our knowledge of the actual 
captive performance of some endangered species and details of the living biology of others. However, the usual lack of zoo data from consistent, generation after generation, captive breeding is very troubling. Of the 241 living rare birds, for which I had useful information, 110 seemed unsuited to propagation at the present state of our captive management technology; birds such at the Titicaca grebe, the monkey-eating eagle, the Japanese ancient murrelet, the pygmy swift and the ivory-billed woodpecker. Eighty-four forms, including the greater prairie chicken, the whooping crane, the kagu and even the pink-billed parrot finch, seem to have characteristics suggesting that they may have propagation potential; while 47 birds are now being propagated or almost certainly could be. In this estimate, and in the previous estimate of the propagation potential of recently extinct birds, we have to assume that genetic factors were not principally responsible for the decline of the species.

It is one thing to estimate which declining species might be suitable for captive propagation and another to set up criteria to determine which of these species should be propagated, to insure their survival. These criteria have already been discussed by Mr Scott, Mr Fitter and Miss Jarvis. The main points are easily summarised. A declining species, to be considered for obligatory or supplemental captive propagation, should be restricted in breeding and/or wintering range, inadequately protected in its range, and, most importantly, of a form belonging to a group for which adequate captive management techniques have been developed. However, experimental captive propagation should also be scheduled for species related to endangered animals for which adequate captive management methods are not yet available, so that we will eventually be able to aid related vanishing animals. In fact, the development of better animal capture, restraint, and translocation techniques are a major zoo responsibility.

The tamarau is an example of a species for which a captive propagation programme should immediately be instituted. One of the 23 gadfly petrels might be considered as an experimental stand-in for the cahow and the diablotin. The larger birds and many reptiles and amphibians will be found to deserve at least as much attention as the big mammals. Zoos should support ecological and life history studies for endangered species which may be aided by propagation and which have no close relatives, such as the indri and the solenodons, and cautious experimental propagation programmes should be established. When the numbers of a species in the wild are exceptionally low and captive propagation is not technologically promising, the animal should not be collected for zoo exhibition or propagation, and the purchase of such animals should be stopped. Such a species is the monkey-eating eagle. Where study reveals that a rare species may be safety cropped, export quotas must be determined and maintained.

Finally, the mechanics of the decisions implied by these criteria should be in the hands of IUCN's Survival Service Commission. 
Unfortunately, these men must play the part of a stern Noah, one with little space in his Ark. From time to time it will be necessary to close the gangway to drab species of lesser interest for whom no zoo guardian may be found. In particular will this apply to small, rapidly reproducing birds and mammals whose captive evolution towards domesticity might be difficult to control. Until zoos establish some truly international representative organisation, the work of the commission will be difficult.

\section{Management for Breeding}

The basic principles and problems of how and where to propagate endangered wild animals were touched upon in a paper we presented at the Meetings of the American Association of Zoological Parks and Aquariums in San Diego last March. A few of these largely technical considerations are of special interest to this group. Historically, few zoos were organised with propagation of rare animals in mind. Education and recreational exhibition is their theme. It was not until after World War II that many zoos even began to attempt to maintain species on a long-term basis. For this reason, we have only limited information on the problems of continuing breeding projects. In general, zoo men feel confident of their success with species related to domestic animals. Highly specialised creatures present a varying picture. River hippos and pygmy hippos, for example, have done remarkably well in zoos. Yet the first second-generation orang-utan was not born until 1963, and cheetahs have been mysteriously unsuccessful in captivity. Most presently endangered species have never been kept in potential breeding groups in zoos. Nevertheless, three animal management principles are clear in how to establish the breeding groups of most species.

First, the propagation project must begin with a large sample, preferably chosen from as widely disparate parts of the form's range as is consistent within the delineation of the race. In some cases, subspecific distinctions in small populations will have to be ignored for it will be important to obtain as variable a gene pool as practicable, and it will be essential to maintain truly large breeding groups in each participating collection. This means, of course, that participating zoos will have to show fewer species in order to make space, but zoos must evolve in this direction in any case. Secondly, the project must establish at least three groups of each species, preferably at sufficient distances to preclude common natural calamities. Finally, a technique for artificially selecting, against those specimens produced from time to time, which are not typical of the wild species, must be developed and based upon thorough studies of the animal's total biology in the wild.

This last point, of selection, requires some explanation, for some conservationists are rightly worried that zoo propagation will eventually result in the production of new domestic creatures little resembling their wild progenitors. These biologists have argued that 
it is only the tamest, least wild, animals which survive capture and acclimatisation to pass along their genes in captivity, animals that are unsuitable to be a base stock for propagating a wild species. While this may be true in a very few cases, it seems more likely that the most adaptable specimens, the "fittest" in Darwin's sense, which survive the rigours of capture and captivity might be the same as those which best survive predation, famine, drought and disease in the wild. In any event, animals captured as adults have already been subjected to the severest of selective pressures, for mortality in wild populations is usually highest in infancy and adolescence. Although captivity represents a drastic environmental change for a wild animal, although it is selective in that only a part of the animals exposed to captivity become parents of another generation except in the matter of environmental change the same statement can be applied to any healthy wild animal population. The fact that animals propagated for long periods in zoos may change slightly should not be used to discourage captive preservation. After all, animals remaining in the wild will also change, and so surely will their habitats.

The last question that faces propagation efforts is specially complex : "Where should animals be propagated?" Zoos, public or private with evidence of technical and financial capability trusteed by non-profiit boards of public-spirited citizens and giving evidence of provisions for continuity of leadership, are our best choice at this time for propagation centres. It is to be hoped that special breeding centres will be established exclusively for maintaining endangered species, for there is a tremendous gap between our propagation know-how and our propagation facilities. Obviously, zoos able to provide the best installations for each species must be carefully chosen. In some cases, managed range conditions will prove especially suitable to propagation efforts and zoo-rancher agreements may provide the basis for their best utilisation. In any case, the endangered species should be protected by international interest and by international supervision. Indeed, the development of an internationally coordinated propagation plan must be our next major step.

Thus the zoo's opportunity in the preservation of wild animals is two-fold. Zoo potentials in conservation education and production of scientific information must be realised and zoo obligations to propagate vanishing wild animals must be met. To those who feel these goals valueless, I can do no better than to quote Bronx Zoo's first Curator of Birds, William Beebe :

"The beauty and genius of a work of art may be reconceived, though its first material expression be destroyed; a vanished harmony may yet again inspire the composer; but when the last individual of a race of living things breathes no more, another heaven and another earth must pass before such a one can be again." 